\title{
Air pollution accelerates progression of atherosclerosis
}

\section{6}

This study

supports

the case for

global efforts

of pollution

reduction in

prevention of

cardiovascular

diseases
Exposure to air pollution has been associated with increased cardiovascular morbidity and mortality; however, the pathological mechanisms of this association have not been well established. The prospective MultiEthnic Study of Atherosclerosis and Air Pollution (MESA Air) now shows that long-term exposure to outdoor particulate matter and traffic-related air pollution is associated with progression of coronary calcification, a marker of accelerated atherosclerosis.

Importantly, the air pollutant concentrations reported in this study were in the ranges commonly found in many metropolitan areas, and were even below some regulatory standards. "This study supports the case for global efforts of pollution reduction in prevention of cardiovascular diseases," conclude the investigators.

Professor Annette Peters, director of the Institute of Epidemiology II,

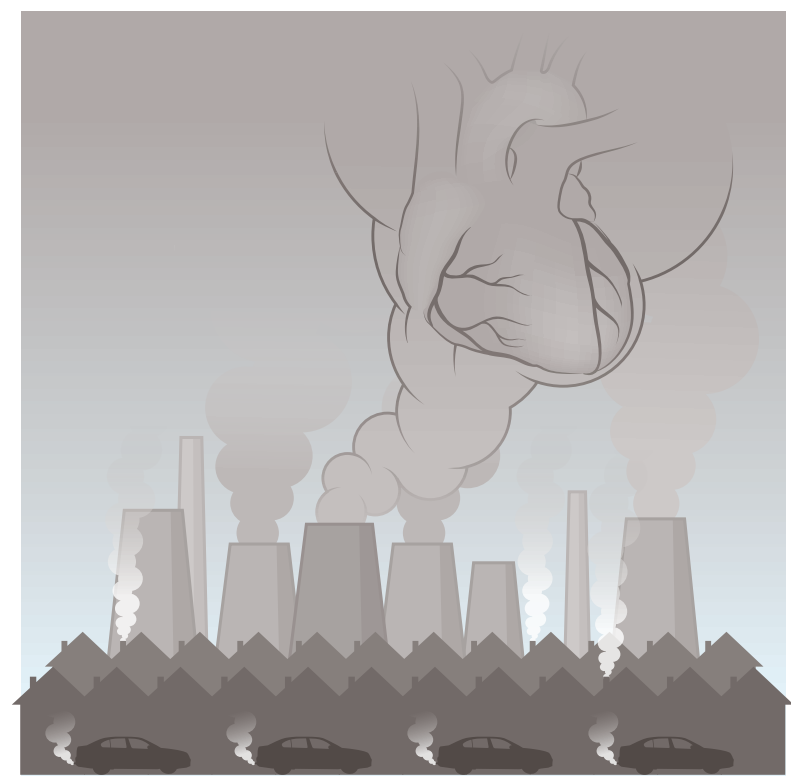

Vicky Summersby/NPG
Helmoltz Zentrum München, Germany, who was not involved in MESA Air, points out that this study has three remarkable features. First, "[MESA Air] is a prospective cohort," says Peters, and the investigators were "able to quantify the impact of air pollution on the development of subclinical cardiovascular disease". Joel D. Kaufman and colleagues assessed the associations between long-term exposure to ambient air pollutants and the progression of two subclinical markers of atherosclerosis - coronary artery calcium and mean carotid artery intima-media thickness; however, they found significant associations only for coronary calcification.

Second, the investigators used "sophisticated air pollution measurements and modelling to derive estimates of residential exposures," explains Peters. The researchers investigated several air pollutants (particulate matter $<2.5 \mu \mathrm{m}$ in diameter, $\mathrm{PM}_{2.5}$; nitrogen oxides, $\mathrm{NO}_{\mathrm{X}}$; and black carbon), and developed and applied residence-specific computational models that included, for example, air monitoring data from local and state agencies, and geographical predictors. The results showed that participants were exposed to long-term average $\mathrm{PM}_{2.5}$ concentrations of $9.2-22.6 \mu \mathrm{g} / \mathrm{m}^{3}$ and to 7.2-139.2 parts per billion (ppb) of $\mathrm{NO}_{\mathrm{X}}$. These exposure levels are lower than some of the international standards such as, for example, the annual $25 \mu \mathrm{g} / \mathrm{m}^{3}$ limit for $\mathrm{PM}_{2.5}$ set in the European Union.

Another important strength of the study, as Peters and the MESA Air investigators point out, is that the MESA cohort was well characterized in terms of potential confounders for the association between air pollution and cardiovascular disease. The study included 6,795 participants from four ethnic groups and six US cities - Baltimore, Maryland; Chicago, Illinois; Los Angeles County, California; New York City, New York; Saint Paul, Minnesota; and Winston-Salem, North Carolina and with no history of clinical cardiovascular disease.

Over 10 years, the participants underwent repeated CT scans to measure coronary artery calcification. Carotid artery intima-media thickness was measured by ultrasonography. In this period, the average progression rate for coronary calcium was 24 Agatston units/year, and the rate of coronary calcium progression was accelerated by 4.1 Agatston units/year for each $5 \mu \mathrm{g} / \mathrm{m}^{3}$ increase of $\mathrm{PM}_{2.5}$ concentration, and by 4.8 Agatston units/year for each $40 \mathrm{ppb}$ increase in $\mathrm{NO}_{\mathrm{X}}$ concentration.

"The study data support specific prevention programmes," says Peters. "Physicians are advised also to consider the environmental condition of their patients in addition to the individual lifestyle-related risk factors." Peters adds that further clinical research is needed to derive evidence-based prevention strategies. Irene Fernández-Ruiz

ORIGINAL ARTICLE Kaufman, J. D. et al. Association between air pollution and coronary artery calcification within six metropolitan areas in the USA (the Multi-Ethnic Study of Atherosclerosis and Air Pollution): a longitudinal cohort study. Lancet http://dx.doi.org/10.1016/ S0140-6736(16)00378-0 (2016) FURTHER READING Cosselman, K. E., Navas-Acien, A. \& Kaufman, J. D. Environmental factors in cardiovascular disease. Nat. Rev. Cardiol. 12, 627-642 (2015) 